\title{
Metrology for biomethane conformity assessment: measure trace gas impurities in biomethane
}

\author{
Jianrong Li ${ }^{*}$, Stefan Persijn, Iris de Krom, Heleen Meuzelaar, Adriaan M.H. van der Veen \\ VSL, Department of Chemistry, Viscosity, Pressure and Mass, Thijsseweg 11, 2629 JA Delft, the \\ Netherlands
}

\begin{abstract}
To facilitate the use of biomethane in existing transmission and distribution infrastructures, CEN/TC 408 developed specifications (EN 16723 ) for injecting biomethane into the natural gas grids and using it as a transport fuel. Currently, the test methods cited in EN 16723 lack metrological aspects and have not been specifically developed for biomethane. To address this need, ISO/TC193/SC1/WG25 "Biomethane" has been created to work on standardized methods. To assess conformity of biomethane with the specification and to provide essential input to WG25, test methods are being developed in this research for a group of impurities such as siloxanes, halogenated volatile organic compounds, hydrogen chloride, hydrogen fluoride. A further objective of this research is to develop fit-for-purpose measurement standards for these parameters, to enable SI-traceable calibration and facilitate accurate measurement results. An overview of the progress made with respect to the development of measurement standards and test methods for trace level concentrations of impurities is presented, with a focus on static measurement standards of siloxanes and halogenated volatile organic compounds, dynamic gas standards of $\mathrm{HCl}$ and $\mathrm{HF}$, as well as corresponding test methods based on gas chromatography and spectroscopic techniques. The work presented is pivotal for the development of metrological infrastructure for biomethane conformity assessment.
\end{abstract}

\section{Introduction}

The demand of renewable energy increases in the EU to reduce carbon dioxide emissions and to contribute to the diversification of the European energy supply. One of the main goals of the Paris Climate Accord of 2016 is, to decarbonise the natural gas grid to reduce greenhouse gas emissions. To ensure that the target is met of at least $32 \%$ renewables in the final energy consumption in the EU by 2030, the second renewable energy directive 2018/2001 [1] aims to make the EU a global leader in renewable energy. These targets go well beyond those of the first renewable energy directive [2] which specified a target of $20 \%$ to be met by 2020 . Therefore, it is clear that there is now an urgent need to

\footnotetext{
*Corresponding author: jli@vsl.nl
} 
significantly increase the amount of renewable energy such as biogas and biomethane utilised within the existing natural gas infrastructure.

Biomethane is defined as "methane rich gas derived from biogas or from gasification of biomass by upgrading with the properties similar to natural gas" [3]. It can be produced by thermochemical conversion (methanation of bio-syngas where bio-syngas is gas that comprising principally carbon monoxide and hydrogen, obtained from gasification of biomass) or biochemical conversion (upgrading of biogas) [4, 5]. Biomethane from upgraded biogas describes the production of biomethane by microbiological processes. The initial product is biogas [3] which requires upgrading to meet the requirements of highcalorific natural gas (see EN 16726 [6]).

Biomethane often contains impurities, such as siloxanes, halogenated volatile organic compounds (halo-VOCs), hydrogen chloride ( $\mathrm{HCl}$ ), hydrogen fluoride (HF), even after the clean-up and upgrading processes. The diversity of the feed stocks used to produce biogas means that a larger number of parameters than for natural gas need to be specified and monitored, in particular with respect to critical impurities. Different feedstocks and different production processes give rise to different sets of relevant impurities. Specifications for biomethane for injection into natural gas network and as automotive fuel have been developed by CEN/TC 408 (EN 16723) [5]. Meeting these specifications is crucial for the integrity of piping networks, metering equipment, and end-user's appliances. Furthermore, the biogas and biomethane matrices bring challenges concerning the applicability of approaches used in the natural gas industry, especially with respect to sampling.

The number of European biogas plants has increased continuously over the past decade, showing that national biogas markets are well established and strong enough to overcome the political uncertainty which has affected certain EU-countries. Recent advances in technologies have resulted in higher plant efficiency, cheaper digesters, and cheaper upgrading units for the conversion of raw biogas to biomethane of natural gas grade. By the end of 2017, nearly 18 thousand of biogas plants were in operation [7], representing an increase of $2 \%$ compared to the previous year. The number of biomethane plants increased by $8 \%$ in 2017 to 540 with a total capacity of $19352 \mathrm{GWh}$ (an increase by $12 \%$ in comparison with the previous year). The ability to blend biomethane with natural gas, has provided a direct route into established and robust European infrastructures, which has helped to facilitate this large market growth [7].

To provide necessary support for this growing market and facilitate biomethane uptake, CEN was mandated by $\mathrm{M} / 475$ [8] to develop a specification for biomethane injection into natural gas networks and for use as a vehicle fuel (EN 16723 [5]). These specifications have provided a sound basis for the conformity assessment of biomethane. However, the test methods needed for conformity assessment cited in EN 16723 are neither harmonized nor validated. They lack metrological aspects and are not specifically developed for biomethane. To address this need, ISO/TC193/SC1 has created a working group WG25 "Biomethane" to develop standardized test methods.

As metrologically traceable measurement results are a prerequisite for conformity assessment, there is a need for developing relevant measurement standards and related calibration methods. This need has been addressed in several EU joint research projects. The first one was mainly concerned with non-conventional energy gases (EMRP ENG01, 2010 - 2013, [9]), followed by projects addressing biogas (EMRP ENG54, 2014 - 2017, [10]) and biomethane (EMPIR 16ENG05, 2017 - 2020, [11]). VSL has been coordinating the latter two projects and within the scope VSL has developed metrologically traceable measurement standards and test methods for a group of parameters, mainly impurities such as siloxanes, halogenated volatile organic compounds (halo-VOCs), carbon monoxide (CO), sulphur-containing compounds, hydrogen cyanide $(\mathrm{HCN})$, hydrogen chloride $(\mathrm{HCl})$, 
hydrogen fluoride (HF), ammonia $\left(\mathrm{NH}_{3}\right)$ and amines. These measurement standards and test methods will enable SI-traceable calibration and accurate measurement results (with stated measurement uncertainties) and will ensure that the characterisation of biogas and biomethane is robust and reliable and therefore the implementation of the EN 16723 specifications for biomethane will be smooth.

Some of these results are presented in this paper, including: preparation of static measurement standards of siloxanes and halo-VOCs, dynamic gas standards of $\mathrm{HCl}$ and $\mathrm{HF}$, as well as the corresponding test methods based on gas chromatography (TD-GCMS/FID) and spectroscopic techniques (Cavity Ring Down Spectroscopy (CRDS), Direct Absorption and Wavelength Modulation Spectroscopy).

\section{Development of measurement standards}

The gas measurement standards containing individual group of components in methane were prepared either statically or dynamically. For the static gas mixtures prepared in cylinders, the preparation is based on static gravimetry in accordance with ISO 6142-1: 2015 [12]. This including the gas standards for siloxanes and halogenated VOCs. For HF and $\mathrm{HCl}$, gas mixtures were prepared dynamically using permeation in accordance with ISO 6145-10:2002 [13].

\subsection{Measurement standards for siloxanes and halogenated VOCs}

Static gas mixtures containing 5 siloxanes, i.e., hexamethyldisiloxane (L2), octamethyltrisiloxane (L3), hexamethylcyclotrisiloxane (D3), ocatmethylcyclotetrasiloxane (D4), and decamethylcyclopentasiloxane (D5), were prepared in methane gas matrix in 5L passivated aluminium cylinders. A method has been developed starting with multicomponent liquid mixtures, instead of the well-known introduction of each liquid separately. This approach has also enabled the introduction of a solid, namely D3. Apart from that, the preparation of the gas mixtures was done as usual for this kind of mixtures. Liquid mixtures (LM) were first prepared with specific amount-of-substance fractions of siloxanes L2, L3, D3, D4, D5 and n-octane (C8, as internal standard), using a Liquid Mixture Robot (LMR) developed at VSL. This device automatically prepares a liquid mixture from a set of liquids and performs all weighings using an analytical balance. The composition of the mixture is then calculated with a VSL designed spreadsheet which takes the weighing data from the LMR and uses the measurement model of ISO6142-1 [12] to compute the composition of the liquid mixture. In a final step, the parent mixtures were then diluted with balance gas (methane) to obtain end mixtures (containing the siloxanes in $\mu \mathrm{mol} \mathrm{mol}{ }^{-1}$ to nmol mol${ }^{-1}$ amount fraction range).

For preparation of static gas mixtures, an automatic weighing device was used to gravimetrically prepare the gas mixtures in accordance with ISO 6142 [12]. The gas mixture preparation facilities are shown in Figure 1. 

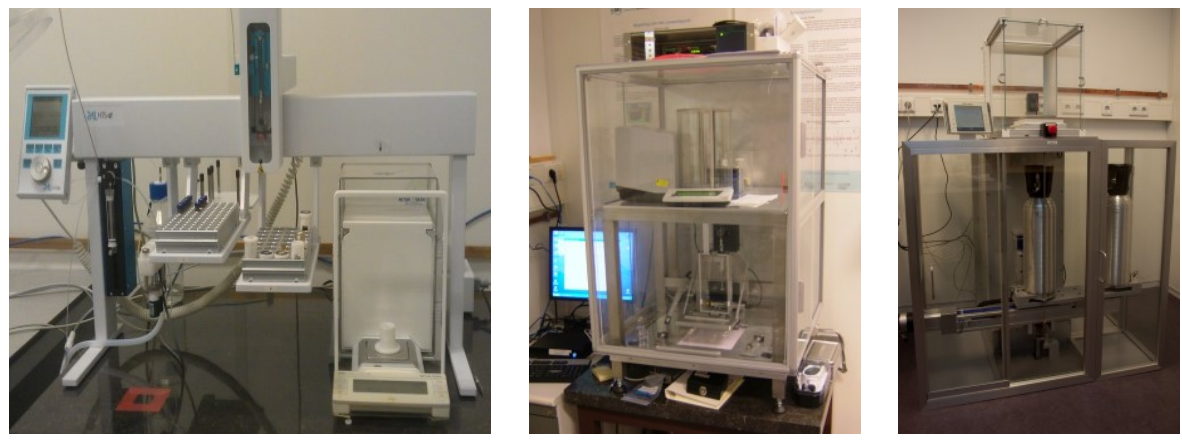

Fig. 1. Gas mixture preparation (gravimetric method): liquid mixture robot (left), syringe weighing robot (middle), automatic weighing device for cylinders (right).

An overview of the measurement standards developed so far for siloxanes is given in Table 1. In the table, the amount of substance range, uncertainty, and the stability for each siloxane are presented. The stated expanded uncertainty includes effects of preparation, impurities in the raw materials and the stability of the gas mixtures.

Table 1. Measurement standards for siloxanes.

\begin{tabular}{|l|c|c|c|}
\hline Component & $\begin{array}{c}\text { Range } \\
\left(\boldsymbol{\mu} \mathbf{m o l ~ m o l}^{-1}\right)\end{array}$ & $\begin{array}{c}\text { Uncertainty } \\
(\mathbf{k}=\mathbf{2})\end{array}$ & $\begin{array}{c}\text { Stability } \\
(\mathbf{m o n t h s})\end{array}$ \\
\hline Siloxane L2 & $50-0.5$ & $2 \% \mathrm{rel}$. & 12 \\
\hline Siloxane L3 & $35-0.3$ & $2 \% \mathrm{rel}$. & 12 \\
\hline Siloxane D3 & $20-0.3$ & $4 \% \mathrm{rel}$. & 12 \\
\hline Siloxane D4 & $9-0.2$ & $8 \% \mathrm{rel}$. & 12 \\
\hline Siloxane D5 & $3-0.1$ & $8 \% \mathrm{rel}$. & 12 \\
\hline
\end{tabular}

Static gas mixtures containing halogenated VOCs were prepared in the same way as for the siloxanes described above. These gas mixtures contain 10 halogenated VOCs often encountered in upgraded biogas or biomethane, including chloromethane, dichloromethane, cis-1,2-dichloroethane, chloroform, trichloroethylene, 1,2-dichloropropane, 1,1,2trichloroethane, tetrachloroethylene, trichlorotrifluoroethane (Freon 113) and vinyl chloride (n-hexane as internal standard). They are prepared in cylinders starting from a liquid mixture containing all the components except for chloromethane and vinyl chloride. Chloromethane and vinyl chloride are gases at room temperature, which were added later during dilution of the mother mixture. The final gas mixtures contain amount-of-substance fractions of $50 \mathrm{nmol} \mathrm{mol}^{-1}$ for all components. In upgraded biogas and biomethane different freons (e.g. 22, 115, 12, 114, 21, 11 and 113) can be present, however due to their ozone depleting properties, they are banned and hence difficult to purchase in the pure form. Consequently, it is difficult to prepare gas mixtures with all practically relevant components.

Preparation of gas mixtures in trace fractions especially for reactive gases is challenging. As loss of sample due to condensation, adsorption and reaction could occur. It requires proper heating, flushing and evacuation of the entire preparation system, as well as proper cylinder treatment. 


\subsection{Dynamic measurement standards for $\mathrm{HCl}$ and $\mathrm{HF}$}

Hydrogen chloride measurement standards can be prepared using both static and dynamic gas mixture preparation techniques. At VSL a dynamic method is being developed for generating hydrogen chloride gas mixtures based on the permeation method as described in ISO 6145-10 [13] using a passivated and calibrated magnetic suspension balance (MSB) that performs continuous accurate mass measurements of the permeation tube. A permeation tube containing pure hydrogen chloride is suspended from the micro balance inside the temperature and pressure-controlled permeation chamber of the MSB and purged at known and controlled flow rate by a high-quality carrier gas. The permeation rate is determined from the recorded mass loss of the permeation device over time (see Figure 2). The permeation gas is mixed with a well-known gas flow of the desired matrix gas (e.g., nitrogen, (bio)methane) which is regulated by thermal mass flow controllers. Amount fractions are generated at $\mathrm{nmol} \mathrm{mol}{ }^{-1}$ and low $\mu \mathrm{mol} \mathrm{mol}^{-1}$ levels by varying the set point temperature of the permeation system and/or the dilution flow rate. The composition of the generated calibration gas mixture is calculated from the instantaneous values of the permeation rate and the dilution flow rate according to ISO 6145-10 [13].
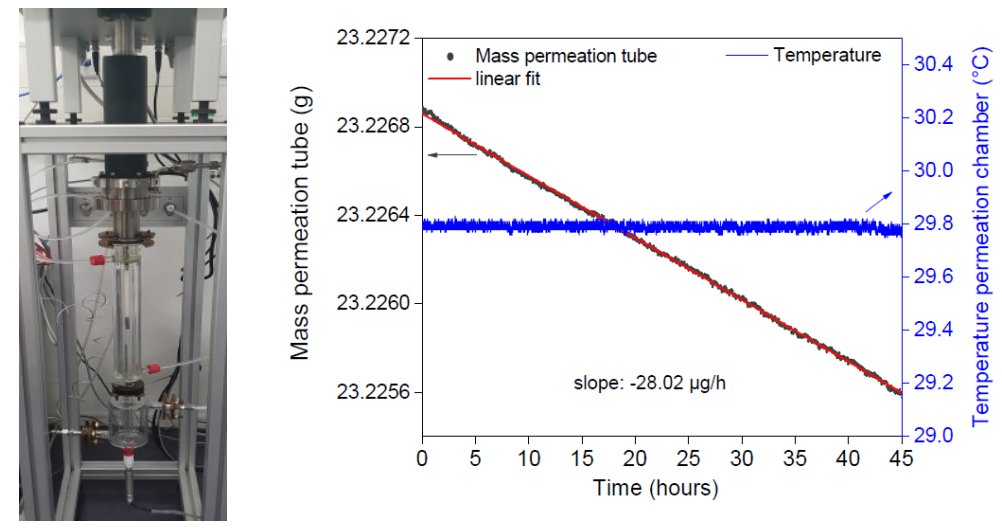

Fig. 2. Magnetic suspension balance used to generate low amount fractions of reactive molecules based on permeation (left) and the determination of the permeation rate of $\mathrm{HCl}$ using a MSB (right).

Measurement standards for hydrogen fluoride were prepared in the similar way as for $\mathrm{HCl}$, i.e., using permeation technique with a magnetic suspension balance. The development of reference materials of hydrogen fluoride is extremely challenging because of its high reactivity and corrosivity. Currently, static measurement standards for the content of hydrogen fluoride in a biogas or biomethane matrix are lacking.

\section{Development of test methods}

For different groups of compounds, various analytical techniques have been applied, such as spectroscopy (Cavity Ring Down Spectroscopy, Direct Absorption and Wavelength Modulation Spectroscopy) and gas chromatography equipped with different types of detectors, and different methods were tested. 

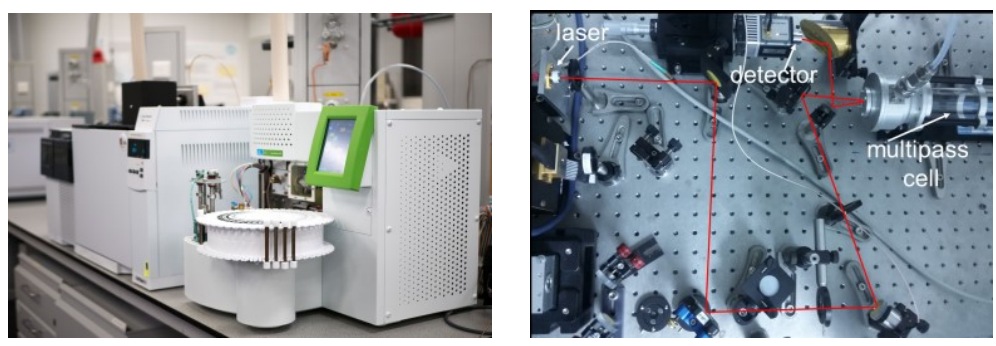

Fig. 3. Analytical instruments: TD-GC-MS/FID (left) and Direct absorption spectroscopy (right).

\subsection{Test method for measuring siloxanes content}

A test method for measuring the siloxanes content was developed using a gas chromatograph with a flame ionisation detector (GC-FID) with gas autosampler and a pressure controlling device. The GC column, liners, tubing and reducers should all be passivated before use. The repeatability and reproducibility of the method are within $3 \%$ relative.

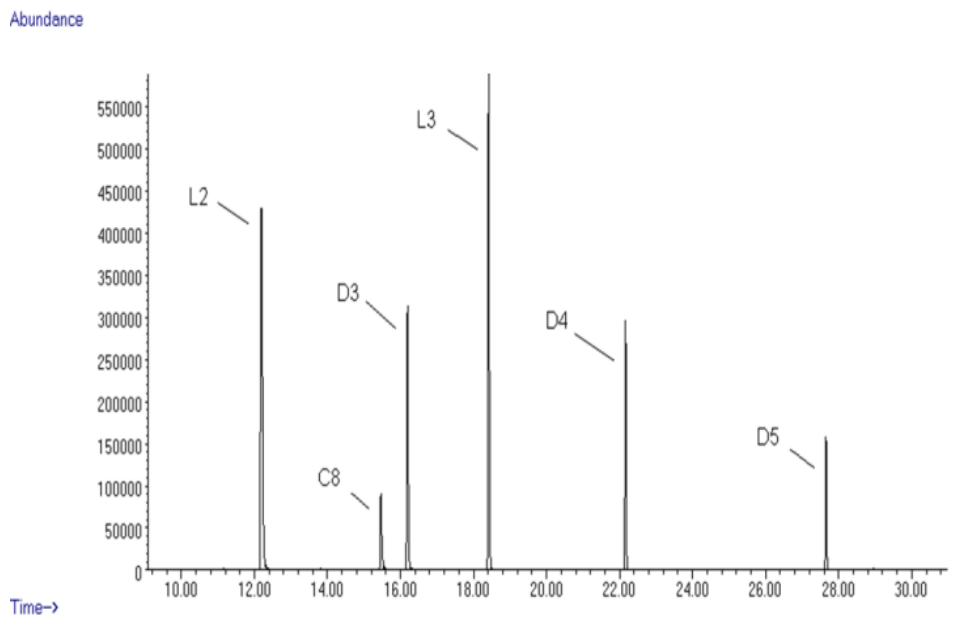

Fig. 4. GC chromatogram of the five siloxanes and the internal standard n-octane.

\subsection{Test method for measuring halogenated VOCs content}

A Test method for measuring halogenated VOCs content was developed using ATD-GCFID/MSD. With FID, relative standard deviations for most of the components are within $0.5 \%$, except for trichloromethane $(0.7 \%)$, chloromethane and vinyl chloride (the chloromethane peak is overlapping with some other component in the FID chromatogram while the vinyl chloride peak is not always visible in the FID chromatogram). Chloromethane and vinyl chloride can be detected using the MSD method. An example of TD-GC-MSD chromatogram is given in Figure 5. 


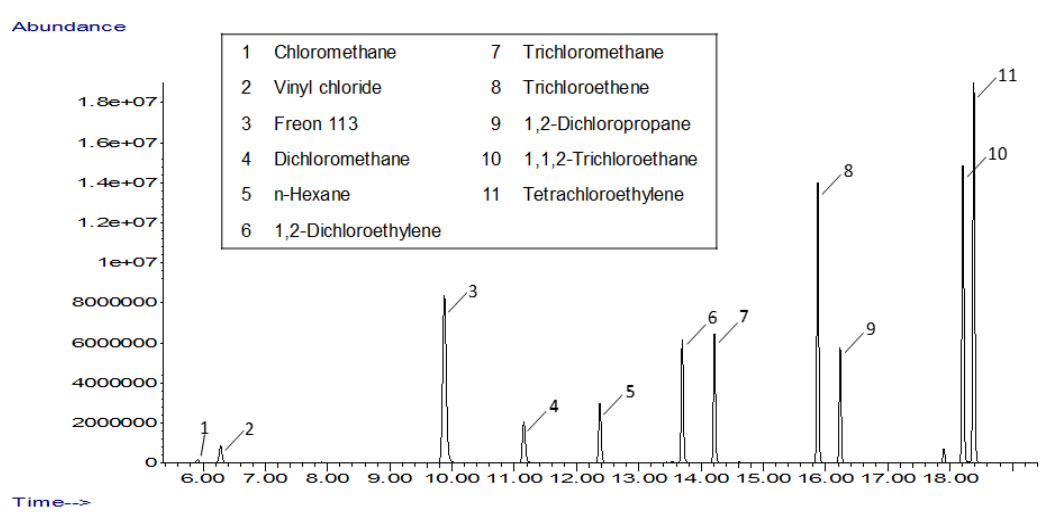

Fig. 5. TD-GC-MSD chromatogram of the ten halogenated VOCs and the internal standard n-hexane.

\subsection{Test method for measuring $\mathrm{HCl}$ content}

The test method for measuring $\mathrm{HCl}$ content is based on an analytical method using the versatile optical parametrical oscillator (OPO) based CRDS spectrometer. The measurement of trace levels of hydrogen chloride in a biogas or biomethane matrix by means of CRDS in the infrared region is, however, more challenging because the interferences of biomethane and biogas matrices (particularly methane) with $\mathrm{HCl}$. For the analysis of hydrogen chloride, a wavelength at $3633.7 \mathrm{~nm}\left(2752.03 \mathrm{~cm}^{-1}\right)$ was chosen, where the absorption of methane is relatively weak but still significant. Measurements are performed at reduced sample pressure $(50 \mathrm{mbar})$ to further reduce spectral interferences from the matrix by narrowing the absorption lines. Furthermore, proper coating application on material surface contact with $\mathrm{HCl}$ is needed to minimize the loss of sample due the adsorption/reaction effects. Figure 6 shows the measurement of a static mixture of 0.95 $\mu \mathrm{mol} \mathrm{mol}{ }^{-1}$ hydrogen chloride in nitrogen. In addition, measurements of pure methane background and $2.5 \mu \mathrm{mol} \mathrm{mol}{ }^{-1}$ hydrogen chloride in methane are presented. The methane matrix causes major spectral interferences, which may cause significant inaccuracies in the determination of the hydrogen chloride content in biogas and/or biomethane. The impact of methane interference is expected to be less problematic with direct absorption and wavelength modulation spectroscopy, which is currently under development. 


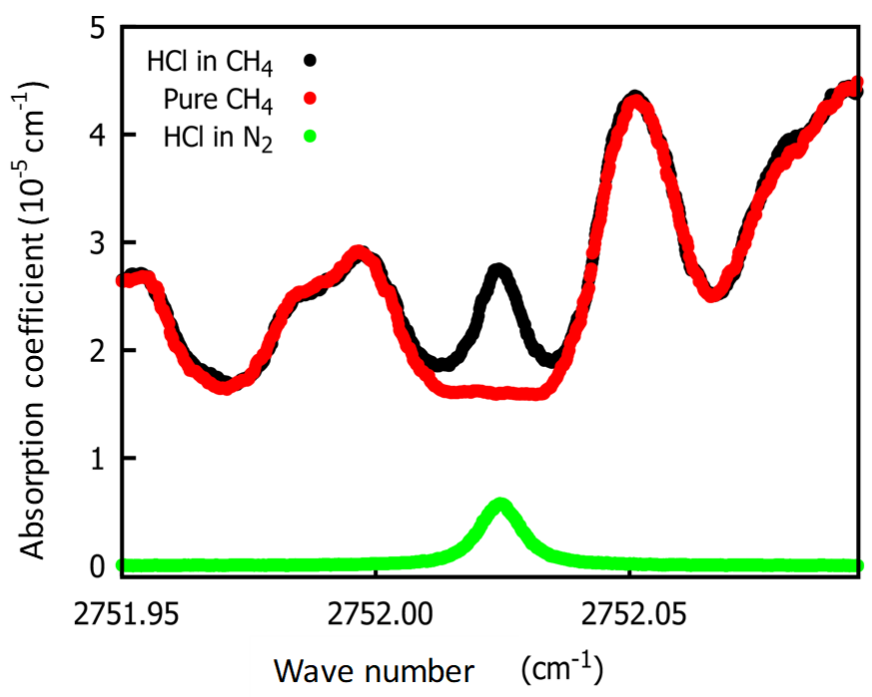

Fig. 6. Measurements of pure methane background (red), $0.95 \mu \mathrm{mol} \mathrm{mol}{ }^{-1} \mathrm{HCl}$ in nitrogen (green) and $2.5 \mu \mathrm{mol} \mathrm{mol}{ }^{-1} \mathrm{HCl}$ in methane (black) using CRDS.

\subsection{Test method for measuring HF content}

A test method for measuring HF content using direct absorption and wavelength modulation spectroscopy is currently under development. For the detection of hydrogen fluoride in biogas or biomethane the absorption line of $\mathrm{HF}$ at $2475.88 \mathrm{~nm}\left(4038.96 \mathrm{~cm}^{-1}\right)$ is probed, which gives at a reduced sample pressure of 100 mbar relatively low interference from nearby absorption bands of methane or other compounds present in the biogas or biomethane matrix. More severe than $\mathrm{HCl}$, proper coating technique for contact surface is highly required. Figure 7 presents the measurement of $\mathrm{HF}$ in nitrogen and methane matrices. As shown for the first time, HF can be analysed in the nmol mol-1 and lower $\mu \mathrm{mol} \mathrm{mol}{ }^{-1}$ range in methane without much interference from the gas matrix.

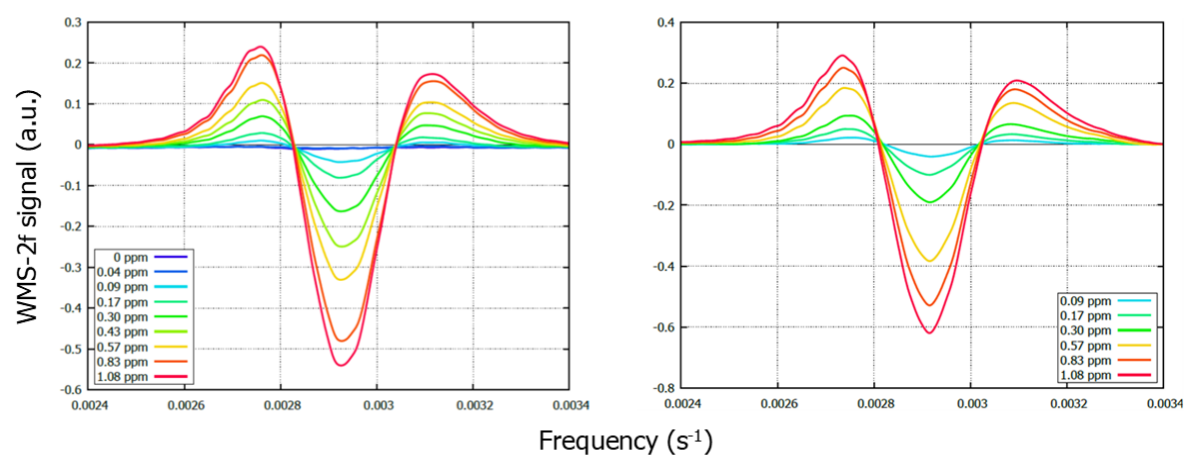

Fig. 7. Measurements of HF in nitrogen (left) and in methane (right, methane background subtracted). 


\section{Conclusions}

VSL has developed measurement standards and test methods for measuring the contents of several critical impurities in biomethane. For the given examples in this paper: measurement standards (static) and test methods for siloxanes (GC-FID) and halogenated VOCs (ATD-GC-FID/MSD) are being developed; dynamic gas standards using permeation and MSB for hydrogen chloride and hydrogen fluoride are developed; OPO-based CRDS method has been tested for hydrogen chloride however suffering from interference with methane; direct absorption and wavelength modulation spectroscopy methods for hydrogen chloride and hydrogen fluoride are under development which show promising results based on initial tests.

Test methods developed in the Metrology for biomethane project are directly fed into standardisation. This research is carried out in close collaboration with the biogas producing and upgrading industry, regulators and biomethane testing laboratories and other end-users to ensure that the developed test methods are robust and efficient and can readily be implemented. It enables metrological infrastructure for biomethane conformity assessment against EN16723 specifications.

\section{Acknowledgement}

This work was performed under EMPIR project 16ENG05 Metrology for biomethane. This project has received funding from the EMPIR programme co-financed by the Participating States and from the European Union's Horizon 2020 research and innovation programme.

\section{References}

1. Directive 2018/2001 of the European Parliament and of the Council on the promotion of the use of energy from renewable sources, Brussels, 11 December 2018.

2. Directive 2009/28/EC of the European Parliament and of the Council on the promotion of the use of energy from renewable sources, Brussels, 23 April 2009.

3. NEN-EN-ISO 14532, Natural gas - Vocabulary, 2017.

4. Thrän et al., Biomethane - status and factors affecting market development and trade. IEA Task 40 and Task 37 Joint Study. September 2014.

5. EN16723, Natural gas and biomethane for use in transport and biomethane for injection in the natural gas network -- Part 1: Specifications for biomethane for injection in the natural gas network, 2016; and Part 2: Automotive fuel specifications, 2017.

6. EN 16726, Gas infrastructure - Quality of gas - Group H, 2015.

7. EBA 2018, "Statistical Report of the European Biogas Association 2018." Brussels, Belgium, December 2018.

8. European Commission, Directorate-general for energy, M/475 EN, Mandate to CEN for standards for biomethane for use in transport and injection in natural gas pipelines, Brussels, 8 November 2010.

9. EURAMET, European Metrology Research Programme (EMRP) - ENG01 Characterisation of Energy Gases (2010 - 2013), https://www.euramet.org/researchinnovation/search-research-projects/details/?eurametCtcp_project_show[project] $=1088$ 
10. EURAMET, European Metrology Research Programme (EMRP) - ENG54 Metrology for biogas (2014 - 2017), http://projects.npl.co.uk/metrology-for-biogas/

11. EURAMET, European Metrology Programme for Innovation and Research (EMPIR) 16ENG05 Metrology for biomethane (2017 - 2020), http://empir.npl.co.uk/biomethane/

12. ISO 6142-1, Gas analysis - Preparation of calibration gas mixtures - Gravimetric method for Class I mixtures. ISO, International Organization for Standardization, Geneva, Switzerland, First edition 2015.

13. ISO 6145-10, Gas analysis - preparation of calibration gasmixtures using 1645 dynamic volumetric methods - Part 10 : Permeation methods. ISO, International Organization for Standardization, Geneva, Switzerland, First edition 2002. 